\title{
Pholedrine: a substitute for hydroxyamphetamine as a diagnostic eyedrop test in Horner's syndrome
}

\author{
A T Bates, Susan Chamberlain, Miranda Champion, Lorraine Foley, E Hughes, \\ Binita Jani, H Mehta, S E Smith
}

\begin{abstract}
Mydriatic responses to eyedrops containing the indirect acting sympathomimetic amines tyramine, hydroxyamphetamine, and pholedrine have been compared in 10 healthy subjects. Pholedrine, the nmethyl derivative of hydroxyamphetamine, at a concentration of $1 \%$ had effects similar to those produced by $0.5 \%$ hydroxyamphetamine itself. Pretreatment with topical guanethidine attenuated its responses and in 13 patients with unilateral Horner's syndrome it distinguished clearly those five patients who had preganglionic from the eight with postganglionic lesions. It is concluded that $1 \%$ pholedrine may be substituted for $0.5 \%$ hydroxyamphetamine, which is no longer available, as a diagnostic agent for use in Horner's syndrome.
\end{abstract}

(F Neurol Neurosurg Psychiatry 1995;58:215-217)

Keywords: Horner's syndrome; hydroxyamphetamine; pholedrine

In most instances of unilateral Horner's syndrome the site of the sympathetic lesion, whether preganglionic or postganglionic, can be gauged from the diagnosis of the prevailing clinical condition. Nevertheless, it is sometimes helpful to have a confirmatory indication of the site from a pharmacological eyedrop test. Thus the sympathomimetic agent hydroxyamphetamine has for some years been used for this purpose. ${ }^{12}$ It acts indirectly by releasing stored noradrenaline from terminals of the postganglionic nerve, ${ }^{3}$ and its effect depends, therefore, on the functional integrity of the third neuron. When the drops are placed in both eyes of a patient with unilateral Horner's syndrome, failure of the affected pupil to respond and a consequent increase in the existing anisocoria indicate that the lesion is postganglionic. By contrast, a positive response of the affected pupil, without change in or even reversal of the anisocoria, show that it is preganglionic. The results of the test are usually clearcut, although in a small proportion of patients, including presumably ones in whom the neurological lesion is mixed or incomplete, the result is inconclusive. ${ }^{4-6}$ The precision of the test depends at least in part on the cut off point used to determine what constitutes a positive mydriatic response.

Hydroxyamphetamine is no longer obtain- able for this purpose ${ }^{7}$ and we have therefore sought a substitute from two other closely related indirect acting sympathomimetics. This paper reports a three part investigation of pholedrine, which is hydroxymethylamphetamine, in healthy subjects and in patients with Horner's syndrome of known cause.

\section{Methods}

SUBJECTS

Ten healthy subjects (four men, six women) aged 18 to 35 took part in a comparative study in which eyedrops containing varying concentrations of hydroxyamphetamine in a logarithmic series $(0.031-1 \%)$, tyramine (1-8\%), and pholedrine $(0.062-2 \%)$ were instilled on different occasions not less than three days apart. Three of them and four other healthy subjects (two men, two women) aged 19 to 48 took part in a further study in which $1 \%$ pholedrine eyedrops were instilled into both eyes after pretreatment of one eye with $5 \%$ guanethidine eyedrops (Ismelin, Ciba-Geigy) twice daily for three days. Guanethidine causes pharmacological denervation, dispelling sympathetic nerve terminal stores of noradrenaline and therefore abolishing the effect of indirect acting sympathomimetic amines. ${ }^{3}$ No subject had past or present evidence of eye or cardiovascular disease and all were healthy on medical examination.

Thirteen patients with unilateral Horner's syndrome (seven men, six women) aged 36 to 70 were recruited to the third study, in which single $1 \%$ pholedrine eyedrops were instilled into both eyes on one occasion. Eight had postganglionic lesions associated with unilateral cluster headaches. Five had preganglionic lesions, two occurring with apical bronchogenic carcinoma, one associated with Herpes zoster infection of segments T3 and $\mathrm{T} 4$, one after cervical sympathectomy and one after a two stage thoracoplasty.

All subjects and patients received a written explanation of the research and gave written consent to participation. The investigation was approved by the ethics committees of West Lambeth Health Authority and the National Hospital for Neurology and Neurosurgery.

EYEDROPS

All sympathomimetic eyedrops were made up freshly before use in $0.9 \%$ physiological saline. The salts and sources used were hydroxyamphetamine hydrobromide (Smith 


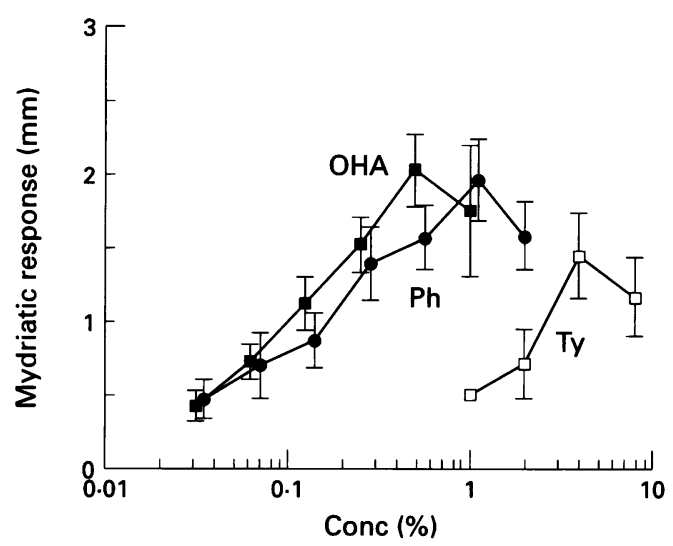

Figure 1 Mydriatic responses (mean (SEM)) of 10 healthy subjects to instillation of hydroxyamphetamine $(\mathrm{OHA})$, pholedrine $(\mathrm{Ph})$, and tyramine (Ty) at different concentrations.

Kline and French), tyramine hydrochloride (Sigma), pholedrine sulphate (Knoll). Concentrations used refer to weights of the salts.

\section{PUPIL MEASUREMENTS}

Vertical pupil diameters of both eyes were recorded in the light with a Whittaker Series 800 binocular infrared television pupillometer as previously described.$^{8}$ Measurements were taken before and at 10 or 15 minutes intervals after eyedrop instillation until maximum drug effects had been reached (usually at 45-60 minutes).

\section{Results}

Hydroxyamphetamine, pholedrine, and tyramine produced dose dependent mydriasis (fig 1 ), although in each case the highest concentrations tested produced submaximal responses. From the linear portion of the log concentration relation the mean potencies relative to hydroxyamphetamine were pholedrine 0.62 and tyramine $0 \cdot 047$. Subjects with darkly pigmented irides showed significantly less mydriasis to all three agents than did those with blue or hazel coloured irides $(F=41.676, p<0.001)$, responses to the optimal dose of pholedrine being reduced to about that of half the dose. On the basis of these results and the previous use of $0.5 \%$ hydroxyamphetamine as a diagnostic test, it was decided to employ pholedrine at a concentration of $1 \%$ and to apply single eyedrops to subjects with light coloured irides, two drops to those with darkly pigmented irides.

In healthy subjects given guanethidine eyedrops the treated pupil was smaller than the untreated one, the anisocoria ranging from 0.5 to $2.3 \mathrm{~mm}$. Pholedrine produced a greater mydriatic response in the untreated than in the guanethidine treated eye. As a result, in every case the anisocoria increased (fig 2); the mean increase was 1.4 (SEM 0.3$) \mathrm{mm}$.

In patients with Horner's syndrome due to postganglionic lesions, pholedrine produced a greater mydriatic response in the normal than
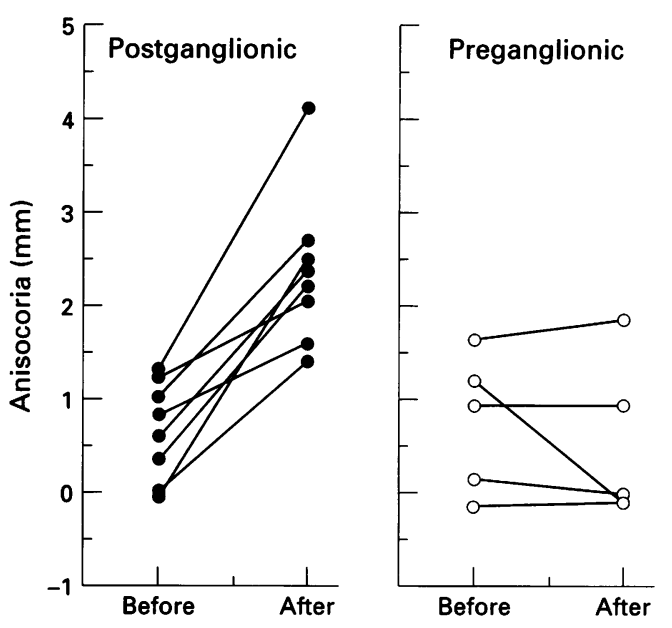

Figure 3 Anisocoria in 13 individual patients with unilateral Horner's syndrome (left, postganglionic; right, preganglionic) before and after instillation of $1 \%$ pholedrine eyedrops into both eyes.

in the affected eye. As a result, in every case the magnitude of the anisocoria increased (fig 3 , left); the mean increase was 1.7 (SEM $0.3 \mathrm{~mm}$ ). In four of the patients with preganglionic lesions, pholedrine produced similar responses in the two eyes; in the fifth, the anisocoria disappeared. Overall, no increase in the anisocoria occurred (fig 3, right), the mean change being -0.24 (SEM 0.27 ) $\mathrm{mm}$. There was no overlap in response between patients with lesions in the two locations. The greatest increase in preganglionic cases was $0.2 \mathrm{~mm}$ and the least in postganglionic cases was $0.8 \mathrm{~mm}$. The difference between the responses was statistically significant $(t=$ $5 \cdot 050, \mathrm{p}=0 \cdot 001$ ).

\section{Discussion}

These findings indicate that, like hydroxyamphetamine, pholedrine applied as $1 \%$ eyedrops produces mydriasis that is greatly attenuated by guanethidine pretreatment and diminished in patients with postganglionic sympathetic nerve lesions. This finding was anticipated because of the close structural similarity of the two drugs (pholedrine is the $\mathrm{N}$-methyl derivative of hydroxyamphetamine) and the indirect nature of their sympathomimetic action. It can therefore be regarded as a satisfactory substitute for hydroxyamphetamine as an eyedrop test for localisation of the lesion in cases of unilateral Horner's syndrome. Similar findings, using pholedrine at the much higher concentration of $5 \%$, have been reported recently. ${ }^{9}$

In clinical practice some hydroxyamphetamine tests on patients with unilateral Horner's syndrome yield inconclusive results, even when the site of the lesion is clearly defined. ${ }^{4-6}$ If pholedrine is used as a substitute, it is unlikely to prove more selective. Consequently, it is recommended that the test should continue to be used as no more than a diagnostic aid. 
We are grateful to the Iris Fund for the Prevention of Blindness for financial support and Knoll Ltd, Maidenhead for supplying pholedrine sulphate.

1 Thompson HS, Mensher JH. Adrenergic mydriasis in Horner's syndrome. The hydroxyamphetamine test for Horner's syndrome. The hydroxyamphetamine test for diagnosis of postga

2 Miller NR. Pharmacologic localization of Horner's Syndrome. In: Walsh and Hoyt's clinical neuro-ophthalmology. 4th ed. Vol 2. Baltimore: Williams and Wilkins, 1985,509-11.

3 Sneddon JM, Turner P. The interactions of local guanethidine and sympathomimetic amines in the human eye. Arch Ophthalmol 1969;81:622-7.

4 Maloney WF, Younge BR, Moyer NJ. Evaluation of the causes and accuracy of pharmacologic localization in Horner's syndrome. Am $\mathcal{f}$ Ophthalmol 1980;90:394-402. 5 Cremer SA, Thompson HS, Digre KB, Kardon RH. Hydroxyamp Am f Ophthalmol 1990;110:71-6.

6 Wilhelm H, Ochsner H, Kopycziok E, TranzettelKlosinski S, Schiefer U, Zrenner E. Horner's syndrome: a retrospective analysis of 90 cases and recommendations for clinical handling. Ger $\mathcal{f}$ Ophthalmol 1992;1: 96-102.

7 Burde RM, Thompson HS. Hydroxyamphetamine. A good drug lost? Am f Ophthalmol 1991;111:100-2.

8 Smith SA, Smith SE, Brown P, Fox C, Sonksen PH. Pupillary signs in diabetic autonomic neuropathy. $B M \dot{F}$ 1978;2:924-7.

9 Wilhelm H, Schäffer E. Pholedrin zur Lokalisation des Horner-Syndrome. Klin Monatsbl Augenheilkd 1994;204: 169-75. 